Editorial

\title{
Is It Required to See for Residual SYNTAX Score after the $\mathrm{PCl}$ ?
}

\author{
Maddury Jyotsna ${ }^{1}$ \\ ${ }^{1}$ Department of Cardiology, Nizam's Institute of Medical Sciences, \\ Punjagutta, Hyderabad, Telangana, India \\ Ind J Car Dis Wom 2019;4:122-123
}

Many studies had shown that cardiovascular events at 1 year were more when the residual SYNTAX score (RSS) was high. ${ }^{1,2}$ The primary goal of the treatment in obstructive coronary artery disease (CAD) should complete revascularization (CR). High RSS, which is an indicator of incomplete revascularization (ICR), is associated with short- and long-term bad prognosis.

Before deciding the mode revascularization for CAD either by the percutaneous coronary intervention ( $\mathrm{PCI}$ ) or coronary artery bypass grafting, better to see what extend each mode of revascularization can do CR. It is advisable to choose that modality of the treatment that can achieve minimal RSS. The importance of this score as a prognostic marker was demonstrated in acute coronary syndrome (ACS), chronic stable angina, and CAD patients with chronic kidney disease $(\mathrm{CKD})^{3,4}$ and even in patients of CAD undergoing transcatheter aortic valve replacement. ${ }^{5}$ This RSS is useful to prognosticate even in patients with obstructive sleep apnea (OSA). Yaping Zeng et al showed that patients with high RSS with OSA had 5.1 times more major adverse cardiovascular and cerebrovascular event (MACCE) risk than non-OSA with CR group. ${ }^{6}$

Kim et al determined the anatomical and physiologic total disease burden by SYNTAX score, RSS, 3-vessel fractional flow reserve (FFR), and functional SYNTAX score in 1,136 patients. Even though angiographically same severity of the diseases was there for both females and males, females had less physiological significant disease. There was no influence of sex on prognostic implications of total anatomical and functional disease burden. ${ }^{7}$

However, there is a difference in RSS calculation by angiogram and by FFR. If functional CR is done using FFR, then RSS may not predict the bad prognosis. Previous studies showed that in stable patients undergoing functionally CR with FFR guidance, RSS did not predict the outcome. Kobayashi $Y$ et al proved that this is true even in ACS patients. ${ }^{8}$ Similarly, Javanainen et al in cardiogenic shock patients also demonstrated that RSS might not have an effect on long-term events. ${ }^{9}$

Definitely, functional RSS is a better indicator of CR, even though angiographic RSS is high, it means that functionally insignificant lesions may be included in the calculation of angiographic RSS. However, all the studies in complex patients like CKD or transcatheter aortic valve implantation or OSA, published in 2019, demonstrate the importance of angiographic RSS as a prognostic marker. So, still, there is a role for angiographic RSS in prognostication for MACE following PCI.

In the present issue of this journal, Sunita et a ${ }^{10}$ showed similar results on RSS. This study is important as this has come from India, who are known to have smaller coronary arteries than westerns and give an idea about the ICR in these small arteries.

\section{Conflict of Interest}

None.

\section{References}

1 Farooq V, Serruys PW, Bourantas CV, et al. Quantification of incomplete revascularization and its association with five-year mortality in the synergy between percutaneous coronary intervention with taxus and cardiac surgery (SYNTAX) trial validation of the residual SYNTAX score. Circulation 2013;128(2):141-151

2 Généreux P, Palmerini T, Caixeta A, et al. Quantification and impact of untreated coronary artery disease after percutaneous coronary intervention: the residual SYNTAX (Synergy Between PCI with Taxus and Cardiac Surgery) score. J Am Coll Cardiol 2012;59(24):2165-2174

3 Hwang D, Kang J, Yang HM, et al. Better prognosis after complete revascularization using contemporary coronary stents in patients with chronic kidney disease. Circ Cardiovasc Interv 2019;12(8):e007907

4 Cardi T, Kayali A, Trimaille A, et al. Prognostic value of incomplete revascularization after percutaneous coronary intervention following acute coronary syndrome: focus on CKD patients. J Clin Med 2019;8(6):E810

(O)2019 Women in Cardiology and Related Sciences
License terms

(요 $\Theta \circledast$ 
5 Witberg G, Zusman O, Codner P, Assali A, Kornowski R. Impact of coronary artery revascularization completeness on outcomes of patients with coronary artery disease undergoing transcatheter aortic valve replacement: a meta-analysis of studies using the residual SYNTAX Score (Synergy Between PCI With Taxus and Cardiac Surgery). Circ Cardiovasc Interv 2018;11(3):e006000

6 Zeng Y, Yang S, Wang X, Fan J, Nie S, Wei Y. Prognostic impact of residual SYNTAX score in patients with obstructive sleep apnea and acute coronary syndrome: a prospective cohort study. Respir Res 2019;20(1):43

$7 \mathrm{Kim} \mathrm{CH}$, Koo BK, Lee JM, et al. Influence of sex on relationship between total anatomical and physiologic disease burdens and their prognostic implications in patients with coronary artery disease. J Am Heart Assoc 2019;8(5):e011002

8 Kobayashi Y, Lønborg J, Jong A, et al; DANAMI-3-PRIMULTI, FAME, and FAMOUS-NSTEMI Study Investigators. Prognostic value of the residual SYNTAX score after functionally complete revascularization in ACS. J Am Coll Cardiol 2018;72(12):1321-1329

9 Javanainen T, Sans-Roselló J, Harjola VP, et al. Prognostic impact of baseline and residual SYNTAX scores in cardiogenic shock. Catheter Cardiovasc Interv 2019;93(1):1-8

10 Aramalla S, Garre I, Shaik SA, Hemanth Harish P. Prognostic value of residual syntax score after percutaneous coronary intervention in multivessel coronary artery disease. Ind J Car Dis Wom 2019;4(3):xxx 